Article

\title{
Vitamin C Status Correlates with Markers of Metabolic and Cognitive Health in 50-Year-Olds: Findings of the CHALICE Cohort Study
}

\author{
John F. Pearson ${ }^{1}$, Juliet M. Pullar ${ }^{2}$, Renee Wilson ${ }^{3}$, Janet K. Spittlehouse ${ }^{4}$, \\ Margreet C. M. Vissers ${ }^{2}$, Paula M. L. Skidmore ${ }^{5}$, Jinny Willis ${ }^{6}$, Vicky A. Cameron ${ }^{3}$ and \\ Anitra C. Carr ${ }^{2, *}$ \\ 1 Biostatistics and Computational Biology Unit, University of Otago, Christchurch 8140, New Zealand; \\ john.pearson@otago.ac.nz \\ 2 Department of Pathology, University of Otago, Christchurch 8140, New Zealand; \\ juliet.pullar@otago.ac.nz (J.M.P.); margreet.vissers@otago.ac.nz (M.C.M.V.) \\ 3 Department of Medicine, University of Otago, Christchurch 8140, New Zealand; \\ renee.wilson@postgrad.otago.ac.nz (R.W.); vicky.cameron@otago.ac.nz (V.A.C.) \\ 4 Department of Psychological Medicine, University of Otago, Christchurch 8140, New Zealand; \\ janet.spittlehouse@otago.ac.nz \\ 5 Department of Human Nutrition, University of Otago, Dunedin 9054, New Zealand; \\ paula.skidmore@otago.ac.nz \\ 6 Lipid \& Diabetes Research Group, Canterbury District Health Board, Christchurch 8140, New Zealand; \\ jinny.willis@cdhb.health.nz \\ * Correspondence: anitra.carr@otago.ac.nz; Tel.: +64-3-364-0649
}

Received: 14 July 2017; Accepted: 31 July 2017; Published: 3 August 2017

\begin{abstract}
A cohort of 50-year-olds from Canterbury, New Zealand $(N=404)$, representative of midlife adults, undertook comprehensive health and dietary assessments. Fasting plasma vitamin $C$ concentrations $(N=369)$ and dietary vitamin $C$ intake $(N=250)$ were determined. The mean plasma vitamin C concentration was $44.2 \mu \mathrm{mol} / \mathrm{L}(95 \%$ CI $42.4,46.0) ; 62 \%$ of the cohort had inadequate plasma vitamin $C$ concentrations (i.e., $<50 \mu \mathrm{mol} / \mathrm{L}$ ), $13 \%$ of the cohort had hypovitaminosis $C$ (i.e., $<23 \mu \mathrm{mol} / \mathrm{L}$ ), and $2.4 \%$ had plasma vitamin $\mathrm{C}$ concentrations indicating deficiency (i.e., $<11 \mu \mathrm{mol} / \mathrm{L}$ ). Men had a lower mean plasma vitamin $C$ concentration than women, and a higher percentage of vitamin $C$ inadequacy and deficiency. A higher prevalence of hypovitaminosis $C$ and deficiency was observed in those of lower socio-economic status and in current smokers. Adults with higher vitamin $\mathrm{C}$ levels exhibited lower weight, BMI and waist circumference, and better measures of metabolic health, including $\mathrm{HbA} 1 \mathrm{c}$, insulin and triglycerides, all risk factors for type 2 diabetes. Lower levels of mild cognitive impairment were observed in those with the highest plasma vitamin $C$ concentrations. Plasma vitamin $C$ showed a stronger correlation with markers of metabolic health and cognitive impairment than dietary vitamin $\mathrm{C}$.
\end{abstract}

Keywords: ascorbate; cognition; HbA1c; insulin; glucose; hypovitaminosis C

\section{Introduction}

The role of vitamin $C$ in health and disease has been actively studied since its discovery over 80 years ago [1]. Vitamin $C$ has a number of well-recognized biological functions, all of which depend upon its ability to act as an electron donor [2]. One of the most significant of these is its cofactor activity for a variety of enzymes with critical functions throughout the body. These include the copper-containing monoxygenases dopamine hydroxylase and peptidyl-glycine $\alpha$-amidating monooxygenase [3] and the Fe (II) and 2-oxoglutarate-dependent family of dioxygenases [4]. The latter 
is a large and varied family, with a continually expanding membership that includes the collagen prolyl hydroxylases responsible for stabilization of the tertiary structure of collagen, the prolyl and asparaginyl hydroxylases which regulate hypoxia-inducible factors (HIF) activity, and DNA and histone demethylases involved in the epigenetic regulation of gene expression. Vitamin $\mathrm{C}$ also functions as a highly effective water-soluble antioxidant, protecting in vivo biomolecules from oxidation [5], and there is good evidence to suggest it is involved in the regeneration of vitamin $\mathrm{E}$ in vivo [6,7].

Because humans are unable to synthesize their own vitamin $C$, it must be obtained from the diet, principally through fruit and vegetable consumption. Inadequate dietary intake results in the potentially fatal deficiency disease, scurvy. As little as $10 \mathrm{mg} /$ day vitamin C is sufficient to prevent overt scurvy [8] and, although scurvy is considered to be relatively rare in Western populations, vitamin $C$ deficiency is the fourth most prevalent nutrient deficiency reported in the United States $[9,10]$. Hypovitaminosis C (defined as a plasma concentration $\leq 23 \mu \mathrm{mol} / \mathrm{L}$ ) affects a significant proportion of the population, with estimates as large as $15-20 \%$ in the United States [9]. Similar data for the New Zealand population are lacking, although dietary vitamin $C$ intake has been used to estimate the prevalence of inadequate intake, defined as not meeting the estimated average requirement (EAR) [11].

The classical symptoms of scurvy, such as joint pain, lassitude, bleeding and ulceration are thought to be due to the loss in activity of the vitamin C-cofactor enzymes, particularly the collagen hydroxylases. It is becoming increasingly acknowledged, however, that vitamin $C$ is required at concentrations above those needed for the prevention of scurvy for the maintenance of good health $[12,13]$. For example, individuals with hypovitaminosis $C$ are known to present with fatigue, depression and deficiencies in wound healing [14,15], suggesting a requirement for vitamin $C$ status to be above $23 \mu \mathrm{mol} / \mathrm{L}$ in plasma to support these functions. There is also epidemiological evidence to support a role for vitamin $C$ in the prevention of some chronic disease, with intakes $>100 \mathrm{mg} /$ day recommended [12]; these intakes will provide adequate plasma levels (i.e., $>50 \mu \mathrm{mol} / \mathrm{L}$ ) $[14,16]$. Although the Australasian Recommended Dietary Intake (RDI) for vitamin C is only $45 \mathrm{mg} /$ day, the New Zealand Ministry of Health, in accord with other international bodies, has a suggested dietary target of $\sim 200 \mathrm{mg}$ /day vitamin $C$ for the reduction of chronic disease risk [17]. As the many cofactor functions of vitamin $C$ become more widely understood, epidemiological studies in areas in which its biological activity can be justified are required.

The CHALICE (Canterbury Health, Ageing and Lifecourse) study is a unique New Zealand study comprising a comprehensive database of determinants of health. It has prospectively recruited $\sim 400$ fifty-year-olds at random from the electoral roll within the Canterbury region. Participants have undergone extensive health, dietary and social assessments [18]. Here we report on the plasma vitamin $C$ status and dietary vitamin $C$ intake of the participants, and examine the relationships between these measures and a range of health indicators.

\section{Materials and Methods}

\subsection{Study Population}

Participants were from a random sample drawn from the New Zealand electoral roll, recruited to take part in a prospective longitudinal study of health and wellbeing (2010-2013), called the Canterbury Health, Ageing and Lifecourse (CHALICE) study (detailed in [18]). Participants had to be aged 49-51 years, intend to reside within the greater Christchurch area for at least 6 of the next 12 months, live in the community (i.e., not in a prison or a rest home) and be able to complete the assessment (e.g., speak English proficiently). Māori, the indigenous people of New Zealand, were over-sampled so that they represented $15 \%$ of the CHALICE study sample. Enrolment statistics estimate that, in 2012, 94.9\% of the target population were registered to vote in the Christchurch City Council area [19]. Relative to the rest of New Zealand, the Canterbury area has a slightly higher proportion of people aged $\geq 40$ years and a higher proportion of people living in the least economically deprived national quintile [20]. 
Ethical approval was obtained from the Upper South A Regional Ethics Committee (URA/10/03/021) and all participants provided written informed consent.

Data were collected during a 4-6 h interview, via self-completed questionnaires and lifestyle diaries, and from blood and urine tests. The full cohort was 404 participants, and the present analysis is based on the 369 participants for whom fasting plasma vitamin $C$ measurements were obtained and a sample of 250 for whom dietary vitamin $C$ intake was determined.

\subsection{Blood Sample Collection}

Fasting blood samples were collected into EDTA anticoagulant tubes and sent to Canterbury Health Laboratories, an International Accreditation New Zealand (IANZ) laboratory, for analysis of biomarkers. Additional fasting samples were centrifuged at $4000 \mathrm{rpm}$ for $10 \mathrm{~min}$ at $4{ }^{\circ} \mathrm{C}$ to separate plasma, and the plasma stored at $-80{ }^{\circ} \mathrm{C}$ for vitamin $\mathrm{C}$ analysis.

\subsection{Sample Preparation for Vitamin C Analysis}

Stored EDTA-plasma was rapidly thawed and a $500 \mu \mathrm{L}$ aliquot was treated with an equal volume of ice-cold $0.54 \mathrm{M}$ HPLC-grade perchloric acid solution (containing $100 \mu \mathrm{mol} / \mathrm{L}$ of the metal chelator DTPA) to precipitate protein and stabilize the vitamin C. Samples were mixed, incubated on ice for a few minutes, then centrifuged. A $100 \mu \mathrm{L}$ aliquot of the deproteinated supernatant was treated with $10 \mu \mathrm{L}$ of the reducing agent TCEP $(100 \mathrm{mg} / \mathrm{mL}$ stock $)$ for $2 \mathrm{~h}$ at $4{ }^{\circ} \mathrm{C}$ to recover any oxidized vitamin C [21]. Samples were further diluted with an equal volume of ice-cold $77 \mathrm{mM}$ perchloric acid/DTPA solution for HPLC analysis.

\subsection{Vitamin C HPLC Analysis}

The total vitamin C content (ascorbic acid plus dehydroascorbic acid) of the samples was determined by HPLC with electrochemical detection as described previously [22]. Samples $(20 \mu \mathrm{L})$ were separated on a Synergi $4 \mu$ Hydro-RP 80A column $150 \mathrm{~mm} \times 4.6 \mathrm{~mm}$ (Phenomenex NZ Ltd, Auckland, New Zealand) using a Dionex Ultimate 3000 HPLC unit (with autosampler chilled to $4{ }^{\circ} \mathrm{C}$ and column temperature set at $\left.30^{\circ} \mathrm{C}\right)$ and an ESA coulochem II detector $(+200 \mathrm{mV}$ electrode potential and $20 \mu \mathrm{A}$ sensitivity). The mobile phase comprised $80 \mathrm{mM}$ sodium acetate buffer, $\mathrm{pH} 4.8$, containing DTPA $(0.54 \mathrm{mmol} / \mathrm{L})$ and freshly added ion pair reagent n-octylamine $(1 \mu \mathrm{mol} / \mathrm{L})$, delivered at a flow rate of $1.2 \mathrm{~mL} / \mathrm{min}$. A standard curve of sodium-L-ascorbate, standardized spectrophotometrically at $245 \mathrm{~nm}(\varepsilon=9860)$, was freshly prepared for each HPLC run in $77 \mathrm{mmol} / \mathrm{L}$ HPLC-grade perchloric acid containing DTPA $(100 \mu \mathrm{mol} / \mathrm{L})$. Plasma vitamin C content is expressed as $\mu \mathrm{mol} / \mathrm{L}$.

Fasting plasma vitamin $C$ concentrations were classified as follows; deficient $<11 \mu \mathrm{mol} / \mathrm{L}$, marginal 11-23 $\mu \mathrm{mol} / \mathrm{L}$, inadequate $23-50 \mu \mathrm{mol} / \mathrm{L}$ or adequate $>50 \mu \mathrm{mol} / \mathrm{L}[13,15]$.

\subsection{Metabolic and Heart Health Assessments}

Metabolic health was assessed by body measurements and fasting blood tests. Participants' height, weight and waist circumference were taken by the study interviewer, and body mass index (BMI) calculated $\left(\mathrm{kg} / \mathrm{m}^{2}\right)$. Fasting blood tests comprised triglycerides, high-density lipoprotein (HDL), glucose, $\mathrm{HbA} 1 \mathrm{c}$ and insulin (Canterbury Health Laboratories).

Heart health was assessed by blood pressure and participants had their NZ cardiovascular risk score calculated. Blood pressure measurements were taken while seated. Five year cardiovascular risk $(\%)$ was derived according to the New Zealand adaptation of the Framingham risk score; the following variables are included in the calculation: age, gender, systolic blood pressure, diabetic status, smoking history, and total cholesterol to HDL ratio [23]. 


\subsection{Dietary Intake Assessment}

Participants were asked to complete the Four Day Estimated Food Diary (4DEFD) in the week after their interview; on one weekend day and three weekdays. The 4DEFD included detailed instructions on how to record portion sizes, using common household measures. The completed 4DEFD were checked by a trained nutritionist and additional information obtained from participants where necessary before the data were entered into the nutrient analysis program Kai-culator (version 1.08d, Department of Human Nutrition, University of Otago, Dunedin, New Zealand). Dietary analysis was performed on 250 of the CHALICE participants, who had dietary data entered and cleaned at the time of analysis, for whom the mean daily intake of vitamin $C$ was calculated. Data entry was undertaken by experienced nutritionists and all diaries were further checked for accuracy by one person who also made any necessary changes, to ensure consistency of data entry.

\subsection{Wellbeing, Depression and Cognition}

\subsubsection{Mental Wellbeing}

The Warwick-Edinburgh Mental Wellbeing Scale (WEMWBS) was used to assess general wellbeing. The 14 item questionnaire aims to measure positive mental health by assessing both aspects of well-being: eudaimonic and hedonic [24].

\subsubsection{Depression}

During the assessment, trained interviewers used the Mini-International Neuropsychiatric Interview (MINI) for diagnosis of current and past depressive episodes using DSM IV criteria [25].

\subsubsection{Cognition}

Participants completed the Montreal Cognitive Assessment (MoCA) version 7.1 (original version) [26], a short screening test for mild cognitive impairment. It assesses the cognitive domains of attention and concentration, executive functions, memory, language, visuoconstructional skills, conceptual thinking, calculations, and orientation. A score of 26 or more indicates normal functioning, while a score less than 26 might indicate mild cognitive impairment. MoCA scores were excluded from the analysis if English was the second language or if a previous event (e.g., carbon monoxide poisoning) had affected cognitive ability.

\subsection{Socio-Economic Status}

The Economic Living Standard Index Short Form (ELSI $I_{\mathrm{SF}}$ ) was used to assess standard of living [27]. Developed in New Zealand, the ELSI ${ }_{S F}$ assesses a person's consumption and personal possessions, calculating a total score by combining information from all items of the survey. The ELSISF scores range from 0-31, with those who score 0-16 described as being in hardship, scores of 17-24 as comfortable and scores of 25 or above as socio-economically good or very good. The ELSI SF $_{\text {has }}$ excellent internal consistency (coefficient alpha of 0.88 ).

\subsection{Statistical Analyses}

Statistical analyses were performed using R 3.3.1 software (R Foundation for Statistical Computing, Vienna, Austria). Univariate tests on continuous variables were t-tests with Satterthwhaite's adjustment for unequal variances while Wald odds ratios and Fisher exact p-values were calculated for categorical variables. Sample characteristics were compared with census proportions using the chi squared goodness of fit test. All health measures were examined independently for association with vitamin C (plasma vitamin C concentration or dietary vitamin C intake) using linear or logistic regression models. The models fitted the dietary measure, gender (dichotomous), Māori ethnicity (dichotomous) and current smoking (dichotomous). Models were fitted on males and females separately and the whole 
cohort combined. Modeling assumptions were verified with no material departures observed. For each outcome, the $p$ values were adjusted for multiple comparisons using the Benjamini and Yekutieli method. The nominal $p$ value for statistical significance is the usual 0.05 or $5 \%$ type II error rate. All $p<0.1$ are shown in the tables with $p>0.1$ shown as NS (not significant). The odds of currently smoking for those in the lowest socio-economic strata was 3.8 times that of the highest strata (95\% CI 1.7-9.0), $p=0.002$. Similarly the odds of current smoking were 3.4 times higher in the least educated strata than the most educated (95\% CI 1.75, 6.54), $p=0.0006$. To prevent over fitting, socio-economic status and education were not fitted, however smoking acts as a reasonable proxy for population modeling.

\section{Results}

\subsection{Characteristics of the Study Population}

Of the full CHALICE cohort $(N=404), 46.8 \%$ (189) were male, with $83.7 \%$ (338) self-identifying as New Zealand European and 14.9\% (60) as Māori (Table 1). The majority of the participants were in the highest ELSI ${ }_{\mathrm{SF}}$ category. There were 60 current smokers in the cohort.

Table 1. CHALICE participants compared with Census 2006 50-54-year-olds from same region.

\begin{tabular}{|c|c|c|c|c|c|}
\hline & & Cha & $\%)$ & $\begin{array}{l}\text { Census } \\
2006(\%)\end{array}$ & $p$ \\
\hline \multirow{2}{*}{ Gender } & Female & 215 & 53.2 & 50.9 & \multirow{2}{*}{ NS } \\
\hline & Male & 189 & 46.8 & 49.1 & \\
\hline \multirow{2}{*}{ Ethnicity } & Māori & 60 & 14.9 & 4.5 & \multirow{2}{*}{$<0.0001$} \\
\hline & NZ European & 338 & 83.7 & 74.2 & \\
\hline \multirow{3}{*}{$\begin{array}{l}\text { Socio-Economic } \\
\text { Status }\end{array}$} & Low (ELSI $I_{S F}$ score 0-16) & 30 & 7.4 & 8.2 & \multirow{3}{*}{ NS } \\
\hline & Medium (ELSI ${ }_{\mathrm{SF}}$ score $\left.17-24\right)$ & 122 & 30.2 & 29.4 & \\
\hline & High (ELSI SF $_{\text {score } 25-31)}$ & 252 & 62.4 & 62.5 & \\
\hline \multirow{4}{*}{ Education } & No Qualification & 53 & 13.1 & 23.9 & \multirow{4}{*}{$<0.0001$} \\
\hline & Secondary School Qualification & 110 & 27.2 & 35.2 & \\
\hline & Post-secondary & 168 & 41.6 & 25.6 & \\
\hline & University Degree & 73 & 18.1 & 15.3 & \\
\hline \multicolumn{2}{|l|}{ Current Smoker } & 60 & 14.9 & 16.6 & NS \\
\hline
\end{tabular}

$N=404 ; p\left(\chi_{n-1}^{2}\right)>0.1$ shown as not significant, NS.

Table 1 compares the CHALICE participants to the New Zealand Census 2006 data for similar age and region. The CHALICE participants had higher rates of Māori ethnicity and higher qualifications than the Canterbury average (Table 1), whereas socio-economic status and smoking were within stochastic limits. This suggests the sample is reasonably representative of Canterbury 50-year-olds and hence the national cohort allowing for regional bias.

The CHALICE cohort also had typical levels of health for a community sample (Table 2). Anthropometric measures were close to those of the New Zealand population. Average metabolic and cardiac markers for the cohort were generally within the healthy range. However, the high prevalence of chronic conditions in the New Zealand population was also readily apparent. 
Table 2. Health of CHALICE participants and normal ranges for the New Zealand population.

\begin{tabular}{ccccccccc}
\hline & \multicolumn{3}{c}{ Female } & \multicolumn{5}{c}{ Male } \\
\hline Body Measurements & Mean & Min & Max & NZ Female Mean & Mean & Min & Max & NZ Male Mean \\
\hline Weight kg & 78.6 & 49.1 & 149.9 & $74.8(73.5-76.1)$ & 88.4 & 50.8 & 143.8 & $88.0(86.9-89.1)$ \\
BMI kg/m ${ }^{2}$ & 29.1 & 17.4 & 63.4 & $28.1(27.6-28.6)$ & 28.1 & 19.2 & 48.6 & $28.6(28.2-28.9)$ \\
Waist cm & 92.0 & 63.0 & 144.0 & $86.6(85.5-87.6)$ & 98.3 & 72.5 & 148.0 & $98.4(97.4-99.3)$ \\
\hline Metabolism & Mean & Min & Max & Healthy Range & Mean & Min & Max & Healthy Range \\
\hline Triglycerides mmol/L & 1.3 & 0.4 & 11.7 & $<1.7$ & 1.6 & 0.4 & 11.7 & $<1.7$ \\
HDL mmol/L & 1.4 & 0.8 & 2.7 & $1.0-2.2$ & 1.2 & 0.7 & 1.9 & $0.9-2.0$ \\
Glucose mmol/L & 5.1 & 3.2 & 10.8 & $<6.1$ & 5.4 & 3.7 & 17.9 & $<6.1$ \\
HbA1c mmol/L & 38.2 & 27.0 & 74.0 & $<40$ & 39.9 & 28.0 & 102.0 & $<40$ \\
Insulin pmol/L & 60.9 & 10.0 & 277.0 & $10-80$ & 61.2 & 4.0 & 480.0 & $10-80$ \\
\hline Heart Health & Mean & Min & Max & Healthy Range & Mean & Min & Max & Healthy Range \\
\hline BP (systolic) $\mathrm{mmHg}$ & 131.1 & 104.0 & 183.7 & 120 & 134.2 & 97.7 & 185.7 & 120 \\
BP (diastolic) mmHg & 82.5 & 60.3 & 106.0 & 80 & 85.0 & 61.0 & 128.3 & 80 \\
CVD risk score $\%$ & $2.5-5$ & $<2.5$ & $20-25$ & $<2.5$ & $5-10$ & $2.5-5$ & $20-25$ & $<2.5$ \\
\hline Mental Health & Mean & Min & Max & & Mean & Min & Max & \\
\hline Wellbeing & 53.0 & 16 & 70 & & 52.7 & 30 & 70 & \\
Cognition & 27.1 & 19 & 30 & & 26.6 & 16 & 30 & \\
Current Depression $n(\%)$ & $17(7.9)$ & & & & $12(6.3)$ & & & \\
\hline BMI: body mas index, & & & & & & & &
\end{tabular}

BMI: body mass index, HDL: high-density lipoprotein, BP: blood pressure, CVD: Cardiovascular disease. Body measurements compared with New Zealand mean ( $95 \%$ confidence interval) for $45-55$ age range [28]. Metabolic and heart health compared with normal healthy range $[23,29,30]$. Wellbeing measured by Warwick-Edinburgh scale, cognition by MoCA. Current depression is those currently clinically depressed excluding those diagnosed bipolar $(N=203$ female, 179 male). One female has no waist measurement, three females no fasting metabolic measures, one male no fasting metabolic measures, one male glucose assay failed and two males HbA1c assay failed, otherwise data are for 215 females and 189 males.

\subsection{Vitamin C Status of the Study Population}

Fasting plasma vitamin $\mathrm{C}$ measurements were available for 369 of the CHALICE participants. The mean plasma vitamin C concentration was $44.2 \mu \mathrm{mol} / \mathrm{L}(95 \% \mathrm{CI} 42.4,46.0) ; 62 \%$ of the participants were below the adequate level (i.e., $50 \mu \mathrm{mol} / \mathrm{L}$ ), and $93 \%$ of the participants were below the optimal saturating level (i.e., $70 \mu \mathrm{mol} / \mathrm{L}$; Figure 1). Ten percent of the cohort had marginal vitamin $\mathrm{C}$ concentrations (i.e., $11-23 \mu \mathrm{mol} / \mathrm{L}$ ), and vitamin $\mathrm{C}$ deficiency, defined as a plasma concentration of $<11 \mu \mathrm{mol} / \mathrm{L}$, was apparent in $2.4 \%$ of the cohort (Table 3 ).

Plasma vitamin C status was substantially lower in men than in women $(p=0.005)$, and it also varied by socio-economic status $(p=0.003)$. For example, $8 \%$ of those in the lowest socio-economic category were vitamin C deficient compared to $2.4 \%$ of the entire cohort $(n=369)$. Smoking status was also associated with plasma vitamin $C$ status with current smokers having lower vitamin $C$ levels $(p<0.001$; Table 3$)$.

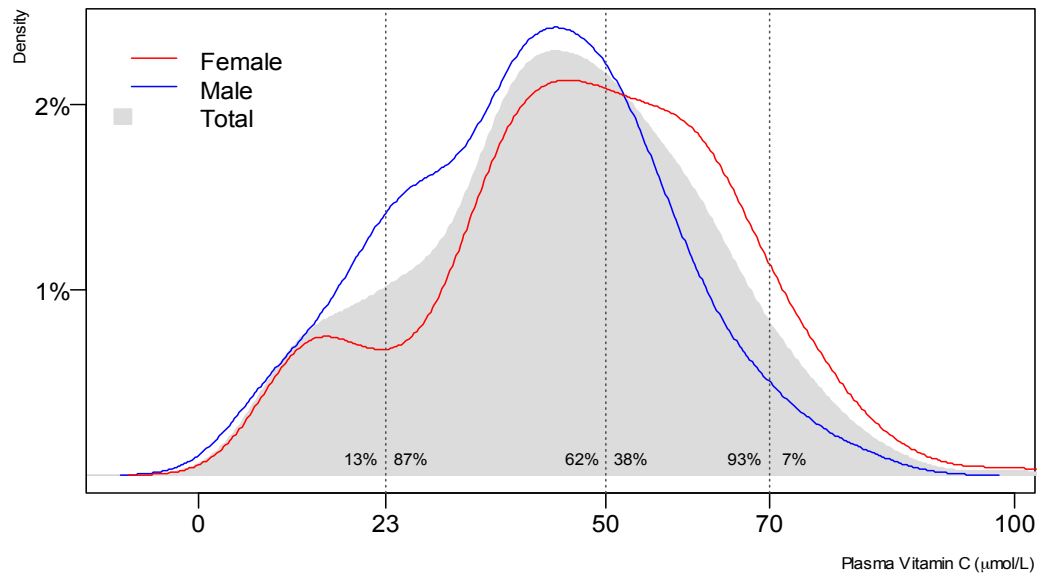

Figure 1. Density plot of plasma vitamin C. Proportion of sample at given vitamin C level; $n=369$. 
Table 3. Categories of vitamin C status.

\begin{tabular}{|c|c|c|c|c|c|c|c|c|c|c|c|c|}
\hline & & \multicolumn{2}{|c|}{ Plasma Vitamin C } & \multicolumn{2}{|c|}{ Deficient } & \multicolumn{2}{|c|}{ Marginal } & \multicolumn{2}{|c|}{ Inadequate } & \multicolumn{2}{|c|}{ Adequate } & \multirow[t]{2}{*}{$p$} \\
\hline & & Mean & $95 \%$ CI & $n$ & $\%$ & $n$ & $\%$ & $n$ & $\%$ & $n$ & $\%$ & \\
\hline Total & & 44.2 & $(42.4,46.0)$ & 9 & 2.4 & 39 & 10.6 & 183 & 49.6 & 138 & 37.4 & \\
\hline \multirow{2}{*}{ Gender } & Female & 47.4 & $(44.9,49.9)$ & 2 & 1.0 & 20 & 10.3 & 85 & 43.6 & 88 & 45.1 & \multirow[t]{2}{*}{0.005} \\
\hline & Male & 40.6 & $(38.2,43.0)$ & 7 & 4.0 & 19 & 10.9 & 98 & 56.3 & 50 & 28.7 & \\
\hline \multirow{2}{*}{ Ethnicity } & Non Māori & 44.5 & $(42.6,46.4)$ & 7 & 2.2 & 31 & 9.8 & 159 & 50.3 & 119 & 37.7 & \multirow[t]{2}{*}{ NS } \\
\hline & Māori & 42.4 & $(37.2,47.6)$ & 2 & 3.8 & 8 & 15.1 & 24 & 45.3 & 19 & 35.8 & \\
\hline \multirow{3}{*}{$\begin{array}{l}\text { Socio- } \\
\text { Economic } \\
\text { Status }\end{array}$} & Low & 36 & $(28.3,45$ & 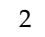 & 8.0 & 7 & 28.0 & 9 & 36.0 & 7 & 28.0 & \multirow[t]{3}{*}{0.003} \\
\hline & Medium & 43.7 & $(40.3$ & 4 & 3.5 & 14 & 12.3 & 53 & 46.5 & 43 & 37.7 & \\
\hline & High & 45.3 & $(43.2,47.4)$ & 3 & 1.3 & 18 & 7.8 & 121 & 52.6 & 88 & 38.3 & \\
\hline \multirow{4}{*}{ Education } & Non & 38.7 & $(33.6,43.9)$ & 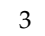 & 6.1 & 6 & 12.2 & 26 & 53.1 & 14 & 28.6 & \multirow[t]{4}{*}{ NS } \\
\hline & Secondary School & 45.9 & $(42.1,49.7)$ & 1 & 1.0 & 13 & 12.6 & 49 & 47.6 & 40 & 38.8 & \\
\hline & & 43. & $(40.6,45.7)$ & 5 & 3.3 & 16 & 10.6 & 75 & 49.7 & 55 & 36.4 & \\
\hline & University Degree & 48.1 & $(44.4,51.9)$ & 0 & 0.0 & 4 & 6.1 & 33 & 50.0 & 29 & 43.9 & \\
\hline \multirow{2}{*}{ Tobacco } & Not Current Smoker & 45.9 & $(44.1,47.8)$ & 6 & 1.9 & 26 & 8.2 & 157 & 49.7 & 127 & 40.2 & \multirow{2}{*}{$<0.001$} \\
\hline & Current Smoker & 34.1 & $(29.2,38.9)$ & 3 & 5.7 & 13 & 24.5 & 26 & 49.1 & 11 & 20.8 & \\
\hline
\end{tabular}

Plasma vitamin C classified as deficient $<11 \mu \mathrm{mol} / \mathrm{L}$, marginal 11-23 $\mu \mathrm{mol} / \mathrm{L}$, inadequate $23-50 \mu \mathrm{mol} / \mathrm{L}$ or adequate $>50 \mu \mathrm{mol} / \mathrm{L} ; n=369$.

Study participants with and without vitamin $C$ measurements do not differ significantly by gender, ethnicity, education, socio-economic status, smoking status, waist, weight or BMI (all $p>0.13$ ), hence are treated as missing at random.

\subsection{Associations of Vitamin C Status with Markers of Metabolic and Mental Health}

The results of the statistical modeling with plasma vitamin $C$ are summarized in Table 4 . Higher plasma vitamin $C$ status was associated with lower weight, BMI and waist circumference in the CHALICE cohort, even after adjustment for gender, ethnicity and current smoking. Of the other markers of metabolic health, plasma vitamin $C$ was negatively associated with blood triglycerides, $\mathrm{HbA} 1 \mathrm{c}$ and insulin, and positively associated with HDL levels. However, after multiple adjustment only triglycerides, $\mathrm{HbA} 1 \mathrm{c}$ and insulin levels remained significant. No correlation was found between plasma vitamin $C$ and the two indicators of heart health; blood pressure and cardiovascular risk score.

Table 4. Significant plasma vitamin $\mathrm{C}$ effects for body measures, metabolic health and mental health.

\begin{tabular}{|c|c|c|c|c|c|c|}
\hline & \multicolumn{2}{|c|}{$\begin{array}{c}\text { Vitamin } C<23 \mu \mathrm{mol} / \mathrm{L} \\
(n=47)\end{array}$} & \multicolumn{2}{|c|}{$\begin{array}{c}\text { Vitamin } C>23 \mu \mathrm{mol} / \mathrm{L} \\
(n=321)\end{array}$} & \multirow[t]{2}{*}{$p$} & \multirow[t]{2}{*}{$p$ Adjusted } \\
\hline & Mean & $95 \% \mathrm{CI}$ & Mean & $95 \%$ CI & & \\
\hline \multicolumn{7}{|l|}{ Body measurements } \\
\hline Weight & 90.3 & $(83.3,97.4)$ & 81.7 & $(79.8,83.6)$ & 0.024 & 0.004 \\
\hline BMI & 31.4 & $(28.7,34.0)$ & 28.1 & $(27.5,28.7)$ & 0.021 & $<0.001$ \\
\hline Waist & 103.3 & $(97.6,108.9)$ & 93.3 & $(91.8,94.8)$ & 0.001 & $<0.001$ \\
\hline \multicolumn{7}{|l|}{ Metabolism } \\
\hline Triglycerides & 1.8 & $(1.4,2.3)$ & 1.4 & $(1.3,1.5)$ & 0.061 & 0.029 \\
\hline HDL & 1.3 & $(1.2,1.3)$ & 1.4 & $(1.3,1.4)$ & 0.033 & NS \\
\hline Glucose & 5.6 & $(5.2,6.0)$ & 5.2 & $(5.0,5.3)$ & 0.072 & 0.073 \\
\hline $\mathrm{HbA} 1 \mathrm{c}$ & 42.2 & $(39.6,44.8)$ & 38.5 & $(37.7,39.3)$ & 0.009 & 0.015 \\
\hline Insulin & 91.0 & $(68.4,113.6)$ & 56.3 & $(51.9,60.8)$ & 0.004 & 0.000 \\
\hline \multicolumn{7}{|l|}{ Heart health } \\
\hline BP (systolic) & 132.2 & $(128.0,136.4)$ & 132.5 & $(130.8,134.2)$ & NS & NS \\
\hline $\mathrm{BP}$ (diastolic) & 83.6 & $(81.0,86.3)$ & 83.5 & $(82.4,84.6)$ & NS & NS \\
\hline CVD risk score & $5-10 \%$ & $(<2.5 \%, 20-25 \%)$ & $2.5-5 \%$ & $(3.5-5 \%, 5-10 \%)$ & 0.057 & NS \\
\hline \multicolumn{7}{|l|}{ Mental Health } \\
\hline \multirow[t]{2}{*}{ Wellbeing } & 50.9 & $(48.4,53.4)$ & 53.0 & $(52.0,53.9)$ & NS & NS \\
\hline & $n$ & $\%$ & $n$ & $\%$ & & \\
\hline MCI & 17 & 40.5 & 66 & 21.5 & 0.012 & 0.02 \\
\hline Current Depression & 6 & 12.5 & 20 & 6.2 & NS & NS \\
\hline
\end{tabular}

MCI: Mild Cognitive Impairment indicated by MoCA score $<26$ for those without excluding conditions. Current depression is for those without Bipolar Disorder. P values less than 0.1 shown otherwise NS: Not Significant. $p$ values adjusted for gender, ethnicity and current smoking. 
Mild cognitive impairment was assessed by the MoCA test. Higher plasma vitamin C status was correlated with lower mild cognitive impairment, which was maintained after adjustment for gender, ethnicity and current smoking (Table 4). A $1 \mu \mathrm{mol} / \mathrm{L}$ increase in plasma vitamin C was associated with $3 \%$ reduced odds of mild cognitive impairment $(\mathrm{OR}=0.97,95 \% \mathrm{CI}=(0.96,0.99), p=0.004)$. Indeed, the odds of mild cognitive impairment were twice as high for those below $23 \mu \mathrm{mol} / \mathrm{L}$ plasma vitamin $\mathrm{C}(\mathrm{OR}=2.1,95 \% \mathrm{CI}=(1.2,3.7), p=0.01)$. Plasma vitamin $\mathrm{C}$ status was not associated with wellbeing or depression.

\subsection{Dietary Vitamin C Intake}

Dietary intake analysis was performed on 250 of the CHALICE participants. The average dietary vitamin C intake was $110 \mathrm{mg}$ /day, with 12\% falling below the New Zealand recommended dietary intake (RDI, Table 5). There was little effect of gender, ethnicity or socio-economic status on dietary intake. However, those with the lowest educational qualifications tended to have lower dietary vitamin $\mathrm{C}$ intake, although this was not quite significant. Current smokers also had a lower dietary intake of vitamin C $(p<0.001)$. Dietary vitamin C intake correlated somewhat less than expected with plasma levels of vitamin $C$, although the correlation was statistically significant (Pearson's correlation coefficient $r=0.27, p=0.00002)$.

Table 5. Categories of dietary vitamin C intake.

\begin{tabular}{|c|c|c|c|c|c|c|c|c|c|c|}
\hline & & \multicolumn{2}{|c|}{ Dietary Vitamin C } & \multicolumn{2}{|c|}{ Below RDI } & \multicolumn{2}{|c|}{ RDI-Average } & \multicolumn{2}{|c|}{ Above Average } & \multirow[t]{2}{*}{$p$} \\
\hline & & Mean & $95 \% \mathrm{CI}$ & $n$ & $\%$ & $n$ & $\%$ & $n$ & $\%$ & \\
\hline Total & & 109.8 & $(101.5,118.1)$ & 30 & 12 & 126 & 50.4 & 94 & 37.6 & \\
\hline \multirow{2}{*}{ Gender } & Female & 107.4 & $(96.6,118.2)$ & 13 & 9.7 & 73 & 54.5 & 48 & 35.8 & \multirow[b]{2}{*}{ NS } \\
\hline & Male & 112.6 & $(99.7,125.6)$ & 17 & 14.7 & 53 & 45.7 & 46 & 39.7 & \\
\hline \multirow{2}{*}{ Ethnicity } & Non Māori & 112.0 & $(102.7,121.2)$ & 22 & 10.3 & 111 & 51.9 & 81 & 37.9 & \multirow{2}{*}{ NS } \\
\hline & Māori & 97.2 & $(79.6,114.7)$ & 8 & 22.2 & 15 & 41.7 & 13 & 36.1 & \\
\hline \multirow{3}{*}{$\begin{array}{l}\text { Socio-Economic } \\
\text { Status }\end{array}$} & Low & 78.8 & $(54.4,103.1)$ & 4 & 26.7 & 8 & 53.3 & 3 & 20.0 & \multirow{3}{*}{ NS } \\
\hline & Medium & 105.0 & $(90.7,119.2)$ & 12 & 15.2 & 36 & 45.6 & 31 & 39.2 & \\
\hline & High & 115.3 & $(104.4,126.1)$ & 14 & 9.0 & 82 & 52.6 & 60 & 38.5 & \\
\hline \multirow{4}{*}{ Education } & None & 83.5 & $(64.2,102.7)$ & 8 & 28.6 & 13 & 46.4 & 7 & 25.0 & \multirow{4}{*}{0.1} \\
\hline & Secondary School & 117.1 & $(98.4,135.7)$ & 6 & 10.0 & 32 & 53.3 & 22 & 36.7 & \\
\hline & Post-secondary & 108.6 & $(97.1,120.1)$ & 11 & 9.9 & 59 & 53.2 & 41 & 36.9 & \\
\hline & University Degree & 118.4 & $(97.6,139.2)$ & 5 & 9.8 & 22 & 43.1 & 24 & 47.1 & \\
\hline \multirow{2}{*}{ Tobacco } & Not Current Smoker & 114.1 & $(105.3,122.8)$ & 20 & 9.0 & 112 & 50.7 & 89 & 40.3 & \multirow{2}{*}{$<0.001$} \\
\hline & Current Smoker & 77.5 & $(54.6,100.5)$ & 10 & 34.5 & 14 & 48.3 & 5 & 17.2 & \\
\hline
\end{tabular}

The cut-off values for the vitamin $C$ categories are as follows: New Zealand recommended dietary intake is $45 \mathrm{mg} /$ day, the average New Zealand intake is $109 \mathrm{mg}$ /day for men and $106 \mathrm{mg} /$ day for women [11]; $n=250$.

\subsection{Associations of Dietary Vitamin C Intake with Markers of Metabolic and Mental Health}

There was evidence that higher dietary intake of vitamin $C$ was associated with lower waist circumference and insulin levels, after adjustment for gender, ethnicity and current smoking (Table 6). Glucose and HbA1c levels were inversely associated with dietary vitamin $\mathrm{C}$ intake in the initial models, however they did not remain so after correction for multiple comparisons. Higher dietary vitamin $\mathrm{C}$ intake was also associated with lower blood pressure, although there was no effect on cardiovascular risk score. There was little association between dietary vitamin $\mathrm{C}$ intake and mental health measures, although dietary intake was inversely associated with mild cognitive impairment in the unadjusted model. 
Table 6. Significant dietary vitamin C effects based on average intake for body measures, metabolic health and heart health.

\begin{tabular}{|c|c|c|c|c|c|c|}
\hline & \multicolumn{2}{|c|}{ Intake < Average $(n=147)$} & \multicolumn{2}{|c|}{ Intake $>$ Average $(n=103)$} & \multirow{2}{*}{$p$} & \multirow{2}{*}{$p$ Adjusted } \\
\hline & Mean & $95 \%$ CI & Mean & $95 \% \mathrm{CI}$ & & \\
\hline \multicolumn{7}{|l|}{ Body measurements } \\
\hline Weight & 82.2 & $(79.2,85.3)$ & 79.8 & $(76.4,83.3)$ & NS & NS \\
\hline BMI & 28.5 & $(27.4,29.6)$ & 27.2 & $(26.2,28.1)$ & 0.08 & 0.063 \\
\hline Waist & 94.6 & $(92.2,97.0)$ & 91.2 & $(88.5,93.8)$ & 0.06 & 0.047 \\
\hline \multicolumn{7}{|l|}{ Metabolism } \\
\hline Triglycerides & 1.4 & $(1.3,1.5)$ & 1.3 & $(1.1,1.6)$ & NS & NS \\
\hline HDL & 1.4 & $(1.3,1.4)$ & 1.4 & $(1.3,1.4)$ & NS & NS \\
\hline Glucose & 5.3 & $(5.1,5.5)$ & 5.0 & $(4.9,5.2)$ & 0.03 & 0.078 \\
\hline $\mathrm{HbA1c}$ & 39.6 & $(38.3,41.0)$ & 37.8 & $(36.9,38.7)$ & 0.03 & NS \\
\hline Insulin & 64.6 & $(55.5,73.6)$ & 52.3 & $(44.3,60.3)$ & 0.05 & 0.041 \\
\hline \multicolumn{7}{|l|}{ Heart health } \\
\hline BP (systolic) & 135.0 & $(132.5,137.5)$ & 130.6 & $(127.4,133.8)$ & 0.03 & 0.016 \\
\hline BP (diastolic) & 85.2 & $(83.6,86.7)$ & 82.3 & $(80.4,84.1)$ & 0.02 & 0.007 \\
\hline CVD risk score & 2.8 & $(2.6,3.0)$ & 2.6 & $(2.2,2.9)$ & NS & NS \\
\hline \multicolumn{7}{|l|}{ Mental Health } \\
\hline \multirow[t]{2}{*}{ Wellbeing } & 52.5 & $(51.1,53.8)$ & 52.9 & $(51.3,54.4)$ & NS & NS \\
\hline & $n$ & $\%$ & $n$ & $\%$ & & \\
\hline MCI & 36 & 24.5 & 14 & 13.6 & 0.04 & NS \\
\hline Current Depression & 13 & 8.8 & 4 & 3.9 & NS & NS \\
\hline
\end{tabular}

MCI Mild Cognitive Impairment indicated by MoCA score $<26$ for those without excluding conditions. Current depression is for those without Bipolar Disorder. $p$ values less than 0.1 shown otherwise NS: Not Significant. $p$ values adjusted for gender, ethnicity and current smoking. Average is New Zealand average of $109 \mathrm{mg} /$ day for men, $106 \mathrm{mg} /$ day for women [11].

\section{Discussion}

These findings were drawn from the first phase of the CHALICE study, a longitudinal observational study of randomly selected 50-year-olds from the Canterbury region, New Zealand in 2010-2013. The comprehensive range of instruments used in the CHALICE study gives a broad picture of the cohort's health and the agreement between the study data and national demographics provides confidence that the study is representative of the health of 50-year-old New Zealanders in 2010. The cohort has typical levels of metabolic and cardiac markers, with indications of overweight/obesity and hypertension in some individuals. Our study provides new evidence that mid-life adults with higher vitamin $C$ levels exhibited better measures of metabolic health and lower levels of mild cognitive impairment.

In New Zealand, dietary vitamin $C$ intake has been estimated by several comprehensive national dietary surveys, including the 2008/2009 New Zealand Adult Nutrition Survey in which the mean usual adult daily intake was $108 \mathrm{mg}$ based on $24 \mathrm{~h}$ dietary recall data [11]. This is close to the average dietary intake of $110 \mathrm{mg}$ / day found in the current study. However, measuring vitamin C concentrations in the body has a number of advantages over dietary intake. It does not rely on participant's recall of their diet, and takes in all sources of the vitamin, including supplements, and the potential impact of vitamin $C$ losses due to food processing and preparation. More particularly, it accounts for confounders of vitamin $C$ status such as smoking, alcohol consumption, prescription medications and health conditions which may affect turnover of the vitamin [31]. The CHALICE study is the first representative study of plasma vitamin C status within the New Zealand population. Only smaller studies in specific, non-representative groups have measured plasma vitamin $C$ concentrations within the New Zealand population [32,33].

In our study, we found that $2.4 \%$ of 50 -year-olds were deficient in vitamin C (i.e., $<11 \mu \mathrm{mol} / \mathrm{L}$ ), putting them at higher risk of developing scurvy and other health effects that may be associated with very low vitamin $C$ status. Men were at greater risk of being deficient than women, and having lower socio-economic status significantly increased risk. Smoking also increased the risk of deficiency, most likely due to increased oxidative stress causing faster turnover of the vitamin [31]. In addition, in our 
cohort, smokers had a lower dietary intake of vitamin C. Numerous studies have previously shown gender, socio-economic status and smoking to be important predictors of vitamin C status [9,33-37]. A recent study suggests the effect of gender on vitamin $C$ status may be due to the differing fat free mass between men and women, meaning vitamin $C$ is distributed throughout a higher volume in men, leading to lower vitamin C concentrations in the plasma [36].

Data from large international cohorts show similar levels of vitamin $\mathrm{C}$ deficiency and hypovitaminosis $\mathrm{C}$ to the CHALICE cohort [37,38], although the United States and lower socio-economic groups in the United Kingdom stand out as having higher rates of deficiency $[9,34]$. In the current study, hypovitaminosis C (i.e., $<23 \mu \mathrm{mol} / \mathrm{L}$ ) was apparent in $13 \%$ of participants, and this increased to $36 \%$ for those in the lowest socio-economic category. Symptoms such as decreased mood and energy levels may be observed with hypovitaminosis $C$, and are possibly related to the role of vitamin $\mathrm{C}$ as a cofactor in carnitine and catecholamine neurotransmitter synthesis [3,14]. A high proportion (63\%) of our participants had inadequate plasma vitamin C concentrations (i.e., $<50 \mu \mathrm{mol} / \mathrm{L}$ ). Indeed, very few of our participants, only $7 \%$, had saturating plasma vitamin $C$ status (i.e., $>70 \mu \mathrm{mol} / \mathrm{L}$ ), implying that current Ministry of Health guidelines recommending consumption of at least five servings of vegetables and fruit per day are ineffective [39]. Since the vitamin C content of fruit and vegetables is quite variable, we suggest that it is important to highlight the consumption of high vitamin C-content fruit and/or vegetables to provide plasma saturation in this age group.

High vitamin $C$ concentrations in the blood were associated with significantly lower weight, waist circumference and BMI, and the effect of plasma vitamin $C$ status was significant enough to survive the correction for multiple comparisons. The association of low vitamin $C$ with obesity in this study replicates results in the literature [35,40-44], and it is apparent that individuals with higher weight require higher intakes of vitamin $C$ to reach adequate vitamin $C$ status $[45,46]$. We also show that higher plasma vitamin $C$ status is associated with lower circulating levels of blood triglycerides, insulin and $\mathrm{HbA1c}$, associations which survive correction for gender, ethnicity and current smoking. These findings are in agreement with a number of smaller intervention studies that have found inverse relationships of vitamin C with various markers of metabolic health [47-49], although others have failed to observe an effect of intervention [50]. Dakhale and coworkers show a small decrease in $\mathrm{HbA} 1 \mathrm{c}$ and fasting blood glucose in individuals with type 2 diabetes after vitamin C supplementation of $1 \mathrm{~g} /$ day for 12 weeks [51]. Observational studies also provide evidence that low vitamin C status is associated with increased risk of metabolic syndrome [52-54].

A role for vitamin $C$ in the prevention or management of diabetes and/or metabolic syndrome has been suggested $[47,51,53,54]$. Obesity is a major risk factor for diabetes, and it may be that vitamin $C$ has a role in moderating the inflammatory effect of adipose tissue. Vitamin $C$ is thought to have anti-inflammatory activity, decreasing levels of inflammatory markers such as C-reactive protein and pro-inflammatory cytokines, although the exact mechanism(s) responsible for this are unknown $[55,56]$. Disorders of energy balance and metabolism are common worldwide. For example, in New Zealand, around 241,000 individuals have been diagnosed with diabetes, and significant numbers have undiagnosed diabetes, or pre-diabetes [57]. Further, among people aged over 15 years, $65 \%$ of individuals meet the criteria for overweight and obesity [58]. Diet and lifestyle factors are associated with these disorders and represent key modifiable determinants. Interestingly, in the CHALICE cohort there were no consistent significant effects identified between plasma vitamin C status and blood pressure or cardiovascular disease risk, although higher dietary vitamin $C$ intake was associated with decreased blood pressure, an effect that has been observed previously [59].

In this study, we also demonstrate lower levels of mild cognitive impairment in those with high vitamin $C$ status, even after adjustment for gender, ethnicity and smoking. Current smoking was a good proxy for socio-economic status and educational achievement in the model; thus, the relationship with vitamin $C$ status survived correction for these important predictors of cognitive impairment. The odds of mild cognitive impairment were twice as high for those below $23 \mu \mathrm{mol} / \mathrm{L}$ plasma vitamin $C$ concentration. Vitamin $C$ is present at very high concentrations in the brain [60], and animal 
models have shown that the brain is the last organ to be depleted of the vitamin during prolonged deficiency [61], suggesting an important requirement for vitamin $C$ in the central nervous system. A recent animal study has shown that moderate vitamin $C$ deficiency may play a role in accelerating amyloid plaque accumulation in Alzheimer's disease, the most common form of dementia [62]. However, epidemiological studies have been inconclusive in regards to whether vitamin $C$ status may affect cognitive decline $[63,64]$ and Alzheimer's disease specifically $[65,66]$. Lu and co-workers investigated the relationship between dietary nutrients and mild cognitive impairment in 2892 elderly Chinese participants using the MoCA test, and found that vitamin $C$ intake exhibited a significant protective effect [64]. Our study has the advantage over many in that plasma vitamin C concentrations have been measured; we were not reliant on dietary intake, which may be susceptible to problems with recall ability and the other confounders mentioned above.

In later life, dementia and disorders of cognition are highly prevalent. Even in the CHALICE sample of 50 -year-olds, $15 \%$ of the sample scored below the recommended cut point on the MoCA. There is considerable interest in the effect of diet on maintaining cognitive function and delaying neuro-degenerative disease in old age. A 2015 study with 37 older healthy adults demonstrated reduced rates of cognitive decline following consumption of orange juice [67]. This was attributed to the high flavanone content of the orange juice, since flavonoids have been associated with reduced rates of cognitive decline $[68,69]$. However, it is possible that the vitamin $C$ content of the orange juice may have contributed to the observed effect. In support of this premise, studies have shown that supplementation of older adults with the antioxidant vitamins $C$ and $E$ was able to preserve cognitive performance [70-72]. Another study, however, found no impact of antioxidant vitamin supplementation on cognition, despite improvements in markers of oxidative stress [73], demonstrating mixed results in the literature. Intervention studies often look for relatively short-term impacts on cognition instruments in response to different nutrient intakes. In contrast, the CHALICE study measured the association of plasma vitamin $C$ status and dietary intake, more likely to be markers of longer-term lifestyle patterns, with a cognitive instrument (MoCA) as an assessment of current mild cognitive impairment.

There are several limitations to our study, notably the observational design, in which associations do not imply causation. Many factors impact on the health status of individuals and groups, including diet, exercise, temperament, behaviors, socio-economic status and genetics. These factors typically interact and correlate with each other, as they do in the CHALICE cohort, with the result that predictors of health outcomes are related (e.g., low blood pressure is associated with low BMI). We have addressed multiple testing issues with the use of corrected $p$ values, and multi-collinearity does not affect individual models as each model only has one independent predictor, with the dichotomous covariates having limited capacity to induce collinearity. While we have focused on the associations of vitamin $C$ with health outcomes, these associations could include the effects of unmeasured nutrients associated with vitamin $C$ intake. Dietary vitamin $C$ and plasma vitamin $C$ status did not always correlate with the same health indicators. However, as detailed above, this is likely due to fasting plasma vitamin $\mathrm{C}$ concentration being a more accurate indicator of body status.

\section{Conclusions}

The CHALICE cohort of 404 individuals aged 50 years had an average vitamin C intake of $\sim 110 \mathrm{mg} /$ day, which should provide adequate plasma concentrations [14]. Despite this, a significant proportion of the participants had inadequate plasma vitamin $C$ status. This indicates the likely effects of confounding factors, such as chronic disease, on plasma vitamin C status, and suggests that dietary interventions targeting increased consumption of fruit and vegetables, and increased vitamin $C$ intake in particular, are required for this age group. Metabolic health markers were significantly better in participants with higher plasma vitamin C concentrations, even after correction for confounders. The association of high vitamin $C$ concentrations with the reduction in risk of impaired cognition is intriguing and merits further investigation. 
Acknowledgments: We would like to acknowledge the participants of the CHALICE study and the CHALICE study investigators. The CHALICE study was supported by grants awarded from the Department of Internal Affairs' Lotteries Health (grant number: AP265022), Canterbury Community Trust, Otago Thyroid Research Foundation and University of Otago Foundation Trust (grant number: TL1060). Funding for the vitamin C analyses was provided by Zespri International Ltd, Mt Maunganui, New Zealand. A.C. is the recipient of a Health Research Council of New Zealand Sir Charles Hercus Health Research Fellowship.

Author Contributions: J.S. coordinated study; A.C., J.M.P. and M.V. measured vitamin C status; R.W. and P.S. calculated dietary intakes; V.C. contributed to design of cardiovascular measures; A.C., P.S. and J.F.P. conceived paper; J.F.P. analyzed data; J.M.P., A.C. and J.F.P. interpreted data and wrote paper; and M.V., P.S., J.W., J.S. and V.C. edited paper. J.F.P., J.M.P. and A.C. contributed to the work equally.

Conflicts of Interest: The authors declare no conflict of interest.

\section{References}

1. Svirbely, J.L.; Szent-Gyorgyi, A. The chemical nature of vitamin C. Biochem. J. 1933, 27, 279-285. [CrossRef] [PubMed]

2. Du, J.; Cullen, J.J.; Buettner, G.R. Ascorbic acid: Chemistry, biology and the treatment of cancer. Biochim. Biophys. Acta 2012, 1826, 443-457. [CrossRef] [PubMed]

3. Englard, S.; Seifter, S. The biochemical functions of ascorbic acid. Annu. Rev. Nutr. 1986, 6, 365-406. [CrossRef] [PubMed]

4. Vissers, M.C.; Kuiper, C.; Dachs, G.U. Regulation of the 2-oxoglutarate-dependent dioxygenases and implications for cancer. Biochem. Soc. Trans. 2014, 42, 945-951. [CrossRef] [PubMed]

5. Carr, A.; Frei, B. Does vitamin C act as a pro-oxidant under physiological conditions? Faseb J. 1999, 13, 1007-1024. [PubMed]

6. Bruno, R.S.; Leonard, S.W.; Atkinson, J.; Montine, T.J.; Ramakrishnan, R.; Bray, T.M.; Traber, M.G. Faster plasma vitamin E disappearance in smokers is normalized by vitamin C supplementation. Free. Radic. Biol. Med. 2006, 40, 689-697. [CrossRef] [PubMed]

7. Lin, J.Y.; Selim, M.A.; Shea, C.R.; Grichnik, J.M.; Omar, M.M.; Monteiro-Riviere, N.A.; Pinnell, S.R. UV photoprotection by combination topical antioxidants vitamin C and vitamin E. J. Am. Acad. Dermatol. 2003, 48, 866-874. [CrossRef] [PubMed]

8. Krebs, H.A. The Sheffield Experiment on the vitamin C requirement of human adults. Proc. Nutr. Soc. 1953, 12, 237-246. [CrossRef]

9. Schleicher, R.L.; Carroll, M.D.; Ford, E.S.; Lacher, D.A. Serum vitamin C and the prevalence of vitamin C deficiency in the United States: 2003-2004 National Health and Nutrition Examination Survey (NHANES). Am. J. Clin. Nutr. 2009, 90, 1252-1263. [CrossRef] [PubMed]

10. CDC's Second Nutrition Report. Available online: https://www.cdc.gov/nutritionreport/report.html (accessed on 28 June 2017).

11. A Focus on Nutrition: Key findings from the 2008/09 NZ Adult Nutrition Survey. Available online: http:/ / www.health.govt.nz/publication/focus-nutrition-key-findings-2008-09-nz-adult-nutrition-survey (accessed on 8 June 2017).

12. Carr, A.C.; Frei, B. Toward a new recommended dietary allowance for vitamin $C$ based on antioxidant and health effects in humans. Am. J. Clin. Nutr. 1999, 69, 1086-1107. [PubMed]

13. Lykkesfeldt, J.; Poulsen, H.E. Is vitamin $C$ supplementation beneficial? Lessons learned from randomised controlled trials. Br. J. Nutr. 2010, 103, 1251-1259. [CrossRef] [PubMed]

14. Levine, M.; Conry-Cantilena, C.; Wang, Y.; Welch, R.W.; Washko, P.W.; Dhariwal, K.R.; Park, J.B.; Lazarev, A.; Graumlich, J.F.; King, J.; et al. Vitamin C pharmacokinetics in healthy volunteers: Evidence for a recommended dietary allowance. Proc. Natl. Acad. Sci. USA 1996, 93, 3704-3709. [CrossRef] [PubMed]

15. Jacob, R.A. Assessment of human vitamin C status. J. Nutr. 1990, 120, 1480-1485. [PubMed]

16. Tetens, I. Scientific opinion on dietary reference values for vitamin C. EFSA. J. 2013, 11, 3418-3486.

17. Nutrient Reference Values for Australia and New Zealand Executive Summary. Available online: https:/ / www.nhmrc.gov.au/guidelines-publications/n35-n36-n37 (accessed on 7 June 2017).

18. Schluter, P.J.; Spittlehouse, J.K.; Cameron, V.A.; Chambers, S.; Gearry, R.; Jamieson, H.A.; Kennedy, M.; Lacey, C.J.; Murdoch, D.R.; Pearson, J.; et al. Canterbury Health, Ageing and Life Course (CHALICE) study: Rationale, design and methodology. N. Z. Med. J. 2013, 126, 71-85. [PubMed] 
19. Enrolment Statistics: Comparison of Estimated Eligible Voting Population to Enrolled Electors for Christchurch City. Available online: http:/ / www.elections.org.nz/councils/ages/district_60_christchurch_ city.html (accessed on 12 March 2013).

20. Population of Canterbury DHB. Available online: http:/ /www.health.govt.nz/new-zealand-health-system/ my-dhb / canterbury-dhb / population-canterbury-dhb (accessed on 12 March 2013).

21. Sato, Y.; Uchiki, T.; Iwama, M.; Kishimoto, Y.; Takahashi, R.; Ishigami, A. Determination of dehydroascorbic acid in mouse tissues and plasma by using tris(2-carboxyethyl)phosphine hydrochloride as reductant in metaphosphoric acid/ethylenediaminetetraacetic acid solution. Biol. Pharm. Bull. 2010, 33, 364-369. [CrossRef] [PubMed]

22. Carr, A.C.; Pullar, J.M.; Moran, S.; Vissers, M.C. Bioavailability of vitamin C from kiwifruit in non-smoking males: Determination of 'healthy' and 'optimal' intakes. J. Nutr. Sci. 2012, 1, e14. [CrossRef] [PubMed]

23. New Zealand Primary Care Handbook 2012. Available online: http:/ /www.health.govt.nz/publication/ new-zealand-primary-care-handbook-2012 (accessed on 9 July 2017).

24. Tennant, R.; Hiller, L.; Fishwick, R.; Platt, S.; Joseph, S.; Weich, S.; Parkinson, J.; Secker, J.; Stewart-Brown, S. The Warwick-Edinburgh mental well-being scale (WEMWBS): Development and UK validation. Health Qual. Life Outcomes 2007, 5, 63. [CrossRef] [PubMed]

25. Sheehan, D.V.; Lecrubier, Y.; Sheehan, K.H.; Janavs, J.; Weiller, E.; Keskiner, A.; Schinka, J.; Knapp, E.; Sheehan, M.F.; Dunbar, G.C. The validity of the Mini International Neuropsychiatric Interview (MINI) according to the SCID-P and its reliability. Eur. Psychiatry 1997, 12, 232-241. [CrossRef]

26. Nasreddine, Z.S.; Phillips, N.A.; Bedirian, V.; Charbonneau, S.; Whitehead, V.; Collin, I.; Cummings, J.L.; Chertkow, H. The Montreal Cognitive Assessment, MoCA: A brief screening tool for mild cognitive impairment. J. Am. Geriatr. Soc. 2005, 53, 695-699. [CrossRef] [PubMed]

27. ELSI Short Form: User Manual for a Direct Measure of Living Standards. Available online: https:/ / www.msd.govt.nz/about-msd-and-our-work/publications-resources/monitoring/livingstandards/elsi-short-form.html (accessed on 7 June 2017).

28. A Portrait of Health: Key results of the 2006/07 New Zealand Health Survey. Available online: http:/ / www. health.govt.nz/publication/ portrait-health-key-results-2006-07-new-zealand-health-survey (accessed on 15 May 2017).

29. The Royal College of Pathologists of Australasia: RCPA. Available online: https://www.rcpa.edu.au/ (accessed on 9 July 2017).

30. Definition and Diagnosis of Diabetes Mellitus and Intermediate Hyperglycaemia. Available online: http:/ / www.who.int/diabetes/publications/diagnosis_diabetes2006/en/ (accessed on 15 May 2017).

31. Kallner, A.B.; Hartmann, D.; Hornig, D.H. On the requirements of ascorbic acid in man: Steady-state turnover and body pool in smokers. Am. J. Clin. Nutr. 1981, 34, 1347-1355. [PubMed]

32. McClean, H.E.; Stewart, A.W.; Riley, C.G.; Beaven, D.W. Vitamin C status of elderly men in a residential home. N. Z. Med. J. 1977, 86, 379-382. [PubMed]

33. McClean, H.E.; Dodds, P.M.; Abernethy, M.H.; Stewart, A.W.; Beaven, D.W. Vitamin C concentration in plasma and leucocytes of men related to age and smoking habit. N. Z. Med. J. 1976, 83, 226-229. [PubMed]

34. Mosdol, A.; Erens, B.; Brunner, E.J. Estimated prevalence and predictors of vitamin C deficiency within UK's low-income population. J. Public Health (Oxf.) 2008, 30, 456-460. [CrossRef] [PubMed]

35. Galan, P.; Viteri, F.E.; Bertrais, S.; Czernichow, S.; Faure, H.; Arnaud, J.; Ruffieux, D.; Chenal, S.; Arnault, N.; Favier, A.; et al. Serum concentrations of beta-carotene, vitamins $\mathrm{C}$ and $\mathrm{E}$, zinc and selenium are influenced by sex, age, diet, smoking status, alcohol consumption and corpulence in a general French adult population. Eur. J. Clin. Nutr. 2005, 59, 1181-1190. [CrossRef] [PubMed]

36. Jungert, A.; Neuhauser-Berthold, M. The lower vitamin C plasma concentrations in elderly men compared with elderly women can partly be attributed to a volumetric dilution effect due to differences in fat-free mass. Br. J. Nutr. 2015, 113, 859-864. [CrossRef] [PubMed]

37. Langlois, K.; Cooper, M.; Colapinto, C.K. Vitamin C status of Canadian adults: Findings from the 2012/2013 Canadian Health Measures Survey. Health Rep. 2016, 27, 3-10. [PubMed]

38. Faure, H.; Preziosi, P.; Roussel, A.M.; Bertrais, S.; Galan, P.; Hercberg, S.; Favier, A. Factors influencing blood concentration of retinol, alpha-tocopherol, vitamin C, and beta-carotene in the French participants of the SU.VI.MAX trial. Eur. J. Clin. Nutr. 2006, 60, 706-717. [CrossRef] [PubMed] 
39. Eating and Activity Guidelines for New Zealand Adults. Available online: http:/ /www.health.govt.nz/ publication/eating-and-activity-guidelines-new-zealand-adults (accessed on 7 July 2017).

40. Block, G.; Jensen, C.D.; Dalvi, T.B.; Norkus, E.P.; Hudes, M.; Crawford, P.B.; Holland, N.; Fung, E.B.; Schumacher, L.; Harmatz, P. Vitamin C treatment reduces elevated C-reactive protein. Free Radic. Biol. Med. 2009, 46, 70-77. [CrossRef] [PubMed]

41. Canoy, D.; Wareham, N.; Welch, A.; Bingham, S.; Luben, R.; Day, N.; Khaw, K.T. Plasma ascorbic acid concentrations and fat distribution in 19,068 British men and women in the European Prospective Investigation into Cancer and Nutrition Norfolk cohort study. Am. J. Clin. Nutr. 2005, 82, 1203-1209. [PubMed]

42. Garcia, O.P.; Ronquillo, D.; Caamano Mdel, C.; Camacho, M.; Long, K.Z.; Rosado, J.L. Zinc, vitamin A, and vitamin $C$ status are associated with leptin concentrations and obesity in Mexican women: Results from a cross-sectional study. Nutr. Metab. (Lond.) 2012, 9, 59. [CrossRef] [PubMed]

43. Johnston, C.S.; Beezhold, B.L.; Mostow, B.; Swan, P.D. Plasma vitamin C is inversely related to body mass index and waist circumference but not to plasma adiponectin in nonsmoking adults. J. Nutr. 2007, 137, 1757-1762. [PubMed]

44. Moor de Burgos, A.; Wartanowicz, M.; Ziemlanski, S. Blood vitamin and lipid levels in overweight and obese women. Eur. J. Clin. Nutr. 1992, 46, 803-808. [PubMed]

45. Block, G.; Mangels, A.R.; Patterson, B.H.; Levander, O.A.; Norkus, E.P.; Taylor, P.R. Body weight and prior depletion affect plasma ascorbate levels attained on identical vitamin C intake: A controlled-diet study. J. Am. Coll. Nutr. 1999, 18, 628-637. [CrossRef] [PubMed]

46. Carr, A.C.; Pullar, J.M.; Bozonet, S.M.; Vissers, M.C. Marginal Ascorbate Status (Hypovitaminosis C) Results in an Attenuated Response to Vitamin C Supplementation. Nutrients 2016, 8, 341. [CrossRef] [PubMed]

47. Ellulu, M.S.; Rahmat, A.; Patimah, I.; Khaza'ai, H.; Abed, Y. Effect of vitamin C on inflammation and metabolic markers in hypertensive and/or diabetic obese adults: A randomized controlled trial. Drug Des. Dev. Ther. 2015, 9, 3405-3412. [CrossRef] [PubMed]

48. Chaudhari, H.V.; Dakhale, G.N.; Chaudhari, S.; Mahatme, M. The beneficial effect of vitamin C supplementation on serum lipids in type 2 diabetic patients: A randomised double blind study. Int. J. Diabetes Metab. 2012, 20, 53-58.

49. Paolisso, G.; Balbi, V.; Volpe, C.; Varricchio, G.; Gambardella, A.; Saccomanno, F.; Ammendola, S.; Varricchio, M.; D'Onofrio, F. Metabolic benefits deriving from chronic vitamin C supplementation in aged non-insulin dependent diabetics. J. Am. Coll. Nutr. 1995, 14, 387-392. [CrossRef] [PubMed]

50. Chen, H.; Karne, R.J.; Hall, G.; Campia, U.; Panza, J.A.; Cannon, R.O.; Wang, Y.; Katz, A.; Levine, M.; Quon, M.J. High-dose oral vitamin C partially replenishes vitamin C levels in patients with Type 2 diabetes and low vitamin $C$ levels but does not improve endothelial dysfunction or insulin resistance. Am. J. Physiol. Heart Circ. Physiol. 2006, 290, H137-H145. [CrossRef] [PubMed]

51. Dakhale, G.N.; Chaudhari, H.V.; Shrivastava, M. Supplementation of vitamin C reduces blood glucose and improves glycosylated hemoglobin in type 2 diabetes mellitus: A randomized, double-blind study. Adv. Pharmacol. Sci. 2011, 2011, 195271. [CrossRef] [PubMed]

52. Godala, M.M.; Materek-Kusmierkiewicz, I.; Moczulski, D.; Rutkowski, M.; Szatko, F.; Gaszynska, E.; Tokarski, S.; Kowalski, J. Lower Plasma Levels of Antioxidant Vitamins in Patients with Metabolic Syndrome: A Case Control Study. Adv. Clin. Exp. Med. 2016, 25, 689-700. [CrossRef] [PubMed]

53. Kim, J.; Choi, Y.H. Physical activity, dietary vitamin C, and metabolic syndrome in the Korean adults: The Korea National Health and Nutrition Examination Survey 2008 to 2012. Public Health 2016, 135, 30-37. [CrossRef] [PubMed]

54. Wei, J.; Zeng, C.; Gong, Q.Y.; Li, X.X.; Lei, G.H.; Yang, T.B. Associations between Dietary Antioxidant Intake and Metabolic Syndrome. PLoS ONE 2015, 10, e0130876. [CrossRef] [PubMed]

55. Mazidi, M.; Kengne, A.P.; Mikhailidis, D. P.; Cicero, A.F.; Banach, M. Effects of selected dietary constituents on high-sensitivity C-reactive protein levels in U.S. adults. Ann. Med. 2017, 1-6. [CrossRef] [PubMed]

56. Mikirova, N.; Casciari, J.; Rogers, A.; Taylor, P. Effect of high-dose intravenous vitamin C on inflammation in cancer patients. J. Transl. Med. 2012, 10, 189. [CrossRef] [PubMed]

57. Ministry of Health: Virtual Diabetes Register. Available online: http:/ /www.health.govt.nz/our-work/ diseases-and-conditions / diabetes / about-diabetes/virtual-diabetes-register-vdr (accessed on 10 July 2017).

58. Understanding Excess Body Weight: New Zealand Health Survey. Available online: http:/ / www.health.govt. $\mathrm{nz} /$ publication/understanding-excess-body-weight-new-zealand-health-survey (accessed on 12 June 2017). 
59. Juraschek, S.P.; Guallar, E.; Appel, L.J.; Miller, E.R. Effects of vitamin C supplementation on blood pressure: A meta-analysis of randomized controlled trials. Am. J. Clin. Nutr. 2012, 95, 1079-1088. [CrossRef] [PubMed]

60. Hornig, D. Distribution of ascorbic acid, metabolites and analogues in man and animals. Ann. N. Y. Acad. Sci. 1975, 258, 103-118. [CrossRef] [PubMed]

61. Vissers, M.C.; Bozonet, S.M.; Pearson, J.F.; Braithwaite, L.J. Dietary ascorbate intake affects steady state tissue concentrations in vitamin C-deficient mice: Tissue deficiency after suboptimal intake and superior bioavailability from a food source (kiwifruit). Am. J. Clin. Nutr. 2011, 93, 292-301. [CrossRef] [PubMed]

62. Dixit, S.; Bernardo, A.; Walker, J.M.; Kennard, J.A.; Kim, G.Y.; Kessler, E.S.; Harrison, F.E. Vitamin C deficiency in the brain impairs cognition, increases amyloid accumulation and deposition, and oxidative stress in APP/PSEN1 and normally aging mice. ACS Chem. Neurosci. 2015, 6, 570-581. [CrossRef] [PubMed]

63. Masaki, K.H.; Losonczy, K.G.; Izmirlian, G.; Foley, D.J.; Ross, G.W.; Petrovitch, H.; Havlik, R.; White, L.R. Association of vitamin $\mathrm{E}$ and $\mathrm{C}$ supplement use with cognitive function and dementia in elderly men. Neurology 2000, 54, 1265-1272. [CrossRef] [PubMed]

64. Lu, Y.; An, Y.; Guo, J.; Zhang, X.; Wang, H.; Rong, H.; Xiao, R. Dietary Intake of Nutrients and Lifestyle Affect the Risk of Mild Cognitive Impairment in the Chinese Elderly Population: A Cross-Sectional Study. Front. Behav. Neurosci. 2016, 10, 229. [CrossRef] [PubMed]

65. Morris, M.C.; Evans, D.A.; Bienias, J.L.; Tangney, C.C.; Bennett, D.A.; Aggarwal, N.; Wilson, R.S.; Scherr, P.A. Dietary intake of antioxidant nutrients and the risk of incident Alzheimer disease in a biracial community study. JAMA 2002, 287, 3230-3237. [CrossRef] [PubMed]

66. Zandi, P.P.; Anthony, J.C.; Khachaturian, A.S.; Stone, S.V.; Gustafson, D.; Tschanz, J.T.; Norton, M.C.; Welsh-Bohmer, K.A.; Breitner, J.C. Reduced risk of Alzheimer disease in users of antioxidant vitamin supplements: The Cache County Study. Arch. Neurol. 2004, 61, 82-88. [CrossRef] [PubMed]

67. Kean, R.J.; Lamport, D.J.; Dodd, G.F.; Freeman, J.E.; Williams, C.M.; Ellis, J.A.; Butler, L.T.; Spencer, J.P. Chronic consumption of flavanone-rich orange juice is associated with cognitive benefits: An 8-wk, randomized, double-blind, placebo-controlled trial in healthy older adults. Am. J. Clin. Nutr. 2015, 101, 506-514. [CrossRef] [PubMed]

68. Letenneur, L.; Proust-Lima, C.; Le Gouge, A.; Dartigues, J.F.; Barberger-Gateau, P. Flavonoid intake and cognitive decline over a 10-year period. Am. J. Epidemiol. 2007, 165, 1364-1371. [CrossRef] [PubMed]

69. Touvier, M.; Druesne-Pecollo, N.; Kesse-Guyot, E.; Andreeva, V.A.; Fezeu, L.; Galan, P.; Hercberg, S.; Latino-Martel, P. Dual association between polyphenol intake and breast cancer risk according to alcohol consumption level: A prospective cohort study. Breast Cancer Res. Treat 2013, 137, 225-236. [CrossRef] [PubMed]

70. Smith, A.P.; Clark, R.E.; Nutt, D.J.; Haller, J.; Hayward, S.G.; Perry, K. Vitamin C, Mood and Cognitive Functioning in the Elderly. Nutr. Neurosci. 1999, 2, 249-256. [CrossRef] [PubMed]

71. Kang, J.H.; Cook, N.R.; Manson, J.E.; Buring, J.E.; Albert, C.M.; Grodstein, F. Vitamin E, vitamin C, beta carotene, and cognitive function among women with or at risk of cardiovascular disease: The Women's Antioxidant and Cardiovascular Study. Circulation 2009, 119, 2772-2780. [CrossRef] [PubMed]

72. Kesse-Guyot, E.; Fezeu, L.; Jeandel, C.; Ferry, M.; Andreeva, V.; Amieva, H.; Hercberg, S.; Galan, P. French adults' cognitive performance after daily supplementation with antioxidant vitamins and minerals at nutritional doses: A post hoc analysis of the Supplementation in Vitamins and Mineral Antioxidants (SU.VI.MAX) trial. Am. J. Clin. Nutr. 2011, 94, 892-899. [CrossRef] [PubMed]

73. Naeini, A.M.; Elmadfa, I.; Djazayery, A.; Barekatain, M.; Ghazvini, M.R.; Djalali, M.; Feizi, A. The effect of antioxidant vitamins $\mathrm{E}$ and $\mathrm{C}$ on cognitive performance of the elderly with mild cognitive impairment in Isfahan, Iran: A double-blind, randomized, placebo-controlled trial. Eur. J. Nutr. 2014, 53, 1255-1262. [CrossRef] [PubMed]

(C) 2017 by the authors. Licensee MDPI, Basel, Switzerland. This article is an open access article distributed under the terms and conditions of the Creative Commons Attribution (CC BY) license (http:/ / creativecommons.org/licenses/by/4.0/). 